\title{
Medical talc and seroma formation following ventral hernia repair
}

\author{
Invited comment to: Medical talc increases the incidence of seroma formation following \\ onlay repair of major abdominal wall hernias. Parameswaran R, Hornby ST Hornby, \\ Kingsnorth AN. DOI 10.1007/s10029-013-1097-4
}

\author{
D. A. Klima $\cdot$ V. A. Augenstein $\cdot$ B. T. Heniford
}

Received: 17 May 2013/Accepted: 17 May 2013/Published online: 28 May 2013

(C) Springer-Verlag France 2013

In the current issue, Parameswaran and colleagues discuss the use of medical talc, $8 \mathrm{~g}$ in a slurry, for seromadesis. In their retrospective review of a prospectively collected database over a 5-month period, 21 consecutive patients were treated prophylactically with talc in the subcutaneous space. They compared this with outcomes in a previous group of 116 patients who had an aerosolized fibrin sealant sprayed in the subcutaneous space. Furthermore, all patients had an onlay repair with a lightweight polypropylene mesh and the drains were placed in the subcutaneous space for a period of 14 days or until drainage was $<50 \mathrm{~mL}$ in $24 \mathrm{~h}$. They report a $76 \%$ seroma and a $43 \%$ wound infection rate, and $33 \%$ of patients required an intervention for their seroma. These numbers are significantly higher than any reported previously in the literature. Consequently, they terminated the study early.

Ventral hernia repair is one of the most common procedures performed by general surgeons today, with 300,000 performed annually in the United States alone. As herniorrhaphy techniques have progressed, an increasing number of patients are undergoing a component separation and/or concomitant panniculectomy, which require a wide subcutaneous dissection during their ventral hernia repair (OVHR/WSD). These procedures carry a high wound complication rate ranging from 33 to $66 \%$ [1]. In our previously published data, postoperative seromas were the most common postoperative modifiable predictor for wound complications after OVHR. Despite multiple

This comment refers to the article available at doi:10.1007/s10029-013-1097-4.

D. A. Klima · V. A. Augenstein · B. T. Heniford ( $\square)$

Carolina Medical Center, Charlotte, NC, USA

e-mail: theniford@carolinas.org previous efforts to reduce seroma formation in the past, seromas were still seen in up to $50 \%$ of surgeries involving extensive subcutaneous dissection [2, 3].

Talc is a hydrous magnesium silicate that is safe, very efficacious and most commonly used agent in the treatment of malignant or chronic pleural effusions (Cochrane review). We began spraying talc in the subcutaneous space of all OVHR/WSD in January 2009. In July 2011, we published our first study on talc in the subcutaneous space on 74 patients who underwent OVHR/WSD and compared it to 106 previous patients who met inclusion criteria [4]. All patients had dissection out to the anterior axillary line and had placement of the mesh in an underlay fashion either in the pre-peritoneal or retrorectus locations. We demonstrated a significant decrease in seroma interventions (20.8 vs. $2.7 \%$ ), cellulitis (39.6 vs. $20.6 \%$ ), drain duration (25.6 vs. 14.6 days) and even early hernia recurrence rates ( 8.5 vs. $0 \%$ ). In subsequent studies, we have demonstrated a decrease in pain scores at 1 month as well as renal insufficiency on days 3 and 4 post-op, which may be due to decreased third space fluid loss in the operative field.

There are a several differences between the two studies; as Paramaswaran and colleagues point out in their discussion, our 2011 study had the mesh placed in an underlay fashion in $100 \%$ of patients; whereas, the current study looked only at patients with an onlay mesh. While previously we and others have done multiple animal and human studies using talc in different spaces throughout the body, this is the first to our knowledge that adds talc to an interface that includes a prosthetic material thereby perhaps impeding the inflammatory reaction between two vascularized surfaces which may be required for seromadesis. In our original description, talc was only used in patients requiring significant subcutaneous dissection, extending to the anterior axillary line. Given that only 6 of the 21 
patients in the current study required this, it seems to be an appreciably different population than the one that was originally described. Perhaps the most important difference is that in the current study the volume of talc used was remarkably higher than we reported; the average patient received $10 \mathrm{~g}$ of talc slurry. Our description and practice is to use $4 \mathrm{~g}$ of aerosolized spray talc. It is certainly possible, and even probable, that utilizing drastically higher amounts of talc in smaller spaces actually accentuates an inappropriate inflammatory response and therefore increases fluid accumulation. Also, our criteria for drain removal are typically $30 \mathrm{ml}$ per $24 \mathrm{~h}$ which is also almost half as much as in this study.

An increased wound infection rate considering the high seroma rate is not unexpected. Neither is an increase in pain and discomfort. However, there are a few unanswered questions before we can come to any conclusions. How did the authors screen for seromas before and after talc was instituted? Were they the same? Was routine ultrasound instituted at any point which would increase the detection of otherwise asymptomatic and inconsequential seromas? Why was so much talc used in these patients and why was a slurry utilized instead of the aerosolized spray? Did the drains obstruct more frequently due to the massive amounts of talc and did the drain volume seem to be higher or lower in the talc group? Was the talc used small particle or large particle? Also, we have shown previously in multiple studies that preoperative pain leads to increased postoperative pain. It would definitely be helpful to use a scale tailored for hernia repair such as the Carolinas Comfort Scale pre- and post-operatively to give us a comparison between the two groups.
Certainly, there is additional work that can be done in this area and we want to congratulate the authors on their manuscript. However, the significant differences between the study that initially reported the successes of talc use and the current manuscript leave such a wide gap in patient selection, talc dose, method of instillation, and operative technique, that there are few binding factors to which one may compare or draw conclusions. There are take away points from this study, and we hope that they will be a guide to further research endeavors in hopes of reducing seromas and consequently wound infection, patient discomfort and hernia recurrence.

Conflict of interest None.

\section{References}

1. Itani K et al (2010) Single stage repair of large contaminated hernia defects with Strattice $^{\mathrm{TM}}$ reconstructive tissue matrix reinforcement of component separation. In: 32nd international congress of European Hernia Society, Istanbul, Turkey

2. Downey SE et al (2005) Review of technique for combined closed incisional hernia repair and panniculectomy status post-open bariatric surgery. Surg Obes Relat Dis 1(5):458-461

3. Fang RC, Lin SJ, Mustoe TA (2010) Abdominoplasty flap elevation in a more superficial plane: decreasing the need for drains. Plast Reconstr Surg 125(2):677-682

4. Klima DA et al (2011) Application of subcutaneous talc in hernia repair and wide subcutaneous dissection dramatically reduces seroma formation and post-operative wound complications. Am Surg 77(7):888-894 